\title{
Sustainable Infrastructure: Climate Changes and Carbon Dioxide
}

\author{
Frederick W. Pontius \\ Department of Civil Engineering and Construction Management, Gordon and Jill Bourns College of Engineering, California Baptist \\ University, Riverside, California, USA
}

Email address:

fpontius@calbaptist.edu

\section{To cite this article:}

Frederick W. Pontius. Sustainable Infrastructure: Climate Changes and Carbon Dioxide. American Journal of Civil Engineering. Vol. 5, No. 5, 2017, pp. 254-267. doi: 10.11648/j.ajce.20170505.11

Received: June 30, 2017; Accepted: August 4, 2017; Published: August 14, 2017

\begin{abstract}
Civil infrastructure provides the physical backbone of all societies. Water supply, wastewater treatment, transportation systems, and civil structures must be sustainable over multiple decades (e.g. 20, 30, 50 years) for human populations to survive and flourish. Over such a long time-period, climate changes are inevitable. The global atmospheric system is dynamic. Weather and climates are constantly adjusting. To date the effects of carbon dioxide have been evaluated almost exclusively using a global reference frame. However, civil infrastructure is stationary and local in nature. A locational reference frame is introduced here as an alternative framework for evaluating the effect of carbon dioxide on civil infrastructure. Temperature data from the City of Riverside, California from 1901 to 2017 are analyzed to illustrate application of a local reference frame. No evidence of significant climate change beyond natural variability was observed in this temperature record. Using a Climate Sensitivity best estimate of $2^{\circ} \mathrm{C}$, the increase in temperature resulting from a doubling of atmospheric $\mathrm{CO}_{2}$ is estimated at approximately $0.009^{\circ} \mathrm{C} / \mathrm{yr}$ which is insignificant compared to natural variability.
\end{abstract}

Keywords: Infrastructure, Sustainability, Climate Change, Carbon Dioxide

\section{Introduction}

Civil societies are built upon sustainable infrastructure. In this context sustainability is a broad concept referring to the ability of a system to perform well over a very long period of time. Sustainable development was first defined in 1987 by the Brundtland Commission as the "ability to make development sustainable - to ensure that it meets the needs of the present without compromising the ability of future generations to meet their own needs" [1]. To meet present needs the City of Riverside, California is implementing a 5-year Capital Improvements Plan (CIP) which includes $\$ 348$ million of funded capital projects between 2016 and 2022 [2]. Over \$1 billion of unfunded CIP needs have also been identified by the city.

Climate has a substantial impact on the longevity of civil infrastructure. Considerable effort has been given in recent decades to investigating and modeling the effects of climate changes especially with respect to carbon dioxide emission. Limiting carbon dioxide emissions has been suggested as a way to control global warming, avoid an increase in adverse weather events, and limit rising sea levels. Assessments to date have almost exclusively applied a global reference frame focused on assessing the warming effects of $\mathrm{CO}_{2}$. A global perspective is of limited use to assess local climate changes impacting infrastructure.

Civil infrastructure is stationary and therefore sustainability must be assessed at the local level [3]. Cities and towns are making real-world decisions about how to spend money on local CIP projects to meet present and future needs. This paper introduces the concept of a locational reference frame for assessing the effects of $\mathrm{CO}_{2}$. Temperature data from the City of Riverside, California is analyzed as an example illustrating the application of a local reference frame.

\section{Measurements and Data Analysis}

The global atmospheric system is dynamic and is constantly in a state of change and adjustment. The sun is the 
primary climate change driving force. Temperature measurement stations have been installed at various locations across the globe. The number of temperature monitoring stations is decreasing and many areas across the globe do not have any temperature monitoring stations. Consequently, average surface temperature is an unreliable metric for assessing global temperature trends.

Average temperature anomalies are used to evaluate global temperature trends. An anomaly is the difference between the temperature measured at a station and the thirty-year mean. The 30-year mean value is calculated over an arbitrary period of time, and records deviations from this average. An example of global surface station temperature anomalies is provided in Figure 1 [4]. These data are widely scattered where the positive anomalies appear to cancel the negative anomalies yielding a net-zero change. Smoothing the data by calculating annual averages results in the trend shown in Figure 2 using the same dependent variable scale applied in Figure 1. The resulting trend is essentially spurious and inconclusive, clearly not a catastrophic increase.

Data does not interpret itself but requires an interpreter to provide meaning. Interpreters bring presuppositions to their analysis. Plotting data presented in Figure 2 using an expanded scale for the dependent variable results in the plot presented in Figure 3. This stretches the scale, making very small changes in the trend line appear significant. Large swings in the trend line point to a very high degree of variability in the annual average (Figure 2) as well as the underlying data (Figure 1). The end result is a widely scattered data set presented as an increase of singular values.

Presentations of climate data typically apply smoothing techniques (e.g. running means) to reveal central tendencies. Analysis results are determined by measurement location (e.g., earth's surface or satellite), the sphere of collection (e.g., land, ocean, or both), the geographic scale (e.g., global, hemispheric, by country, local), time period selected to calculate a thirty-year mean, the smoothing technique applied, and the General Circulation Model (GCM) applied.

Not every aspect of climate can be studied using the scientific method nor validated through physical measurements. Computer models are used to analyze data sets. In science and engineering (and this paper) the term "data" refers to actual physical measurement at a point in time and space. In some temperature data sets, however, computer simulated values have been added in or data may have been arbitrarily adjusted long after the physical measurement was taken. Such practices undermine the credibility of the data set. Computer generated values are estimates, projections, or simulations and are of a different quality than physical measurements. Physical measurements represent a physical quantity whereas computer simulations represent numerical calculation.

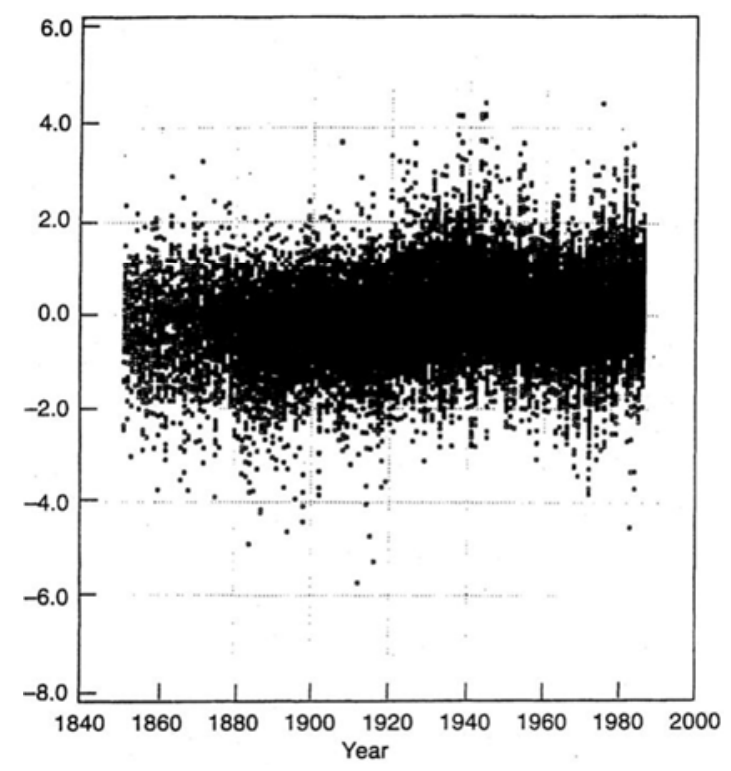

Figure 1. Land-based temperature anomalies 1851-1984 provided by the UK Meteorological Office [5].

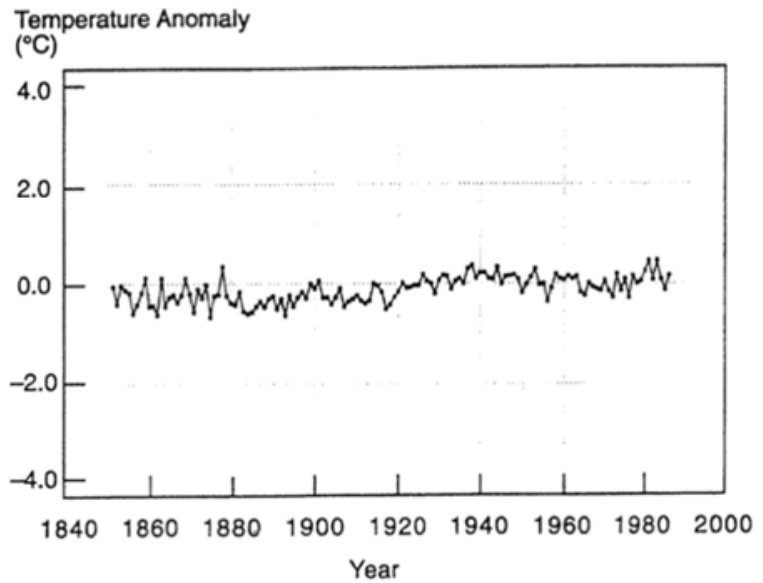

Figure 2. Land-based annual temperature anomalies 1851-1984 of data shown in Figure 1 [4].

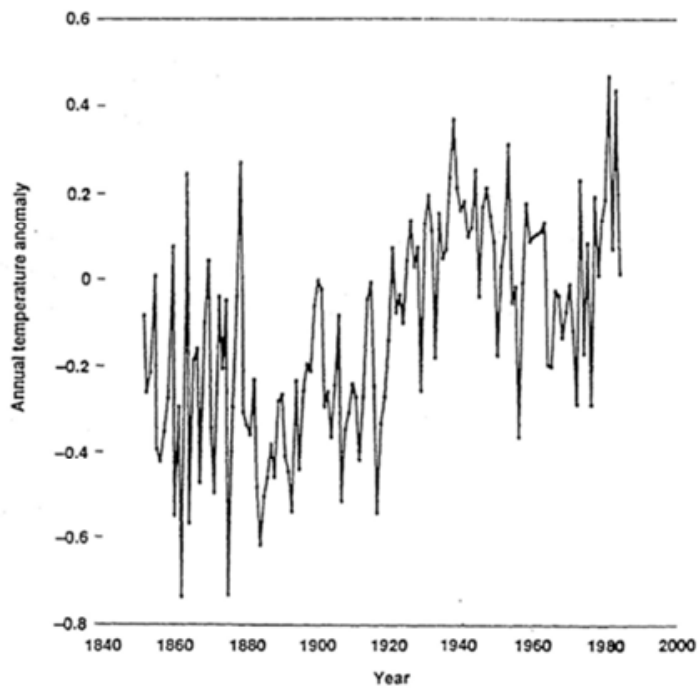

Figure 3. Land-based annual temperature anomalies, 1851-1984 using the same data as shown in Figure 2 but with an expanded ordinate scale [4]. 


\section{Climate and Climate Change}

Climate is often defined as "average weather." In practice climate is a statistical description of the central tendency and variability of relevant measures over a period of time and space ranging from months to thousands of years. The classical time period for defining climate is 30 years [5]. Metrics used to define climate include temperature, precipitation, wind, relative humidity, atmospheric pressure, cloud cover, and solar intensity.

The US Environmental Protection Agency (USEPA) defined "climate change as any significant changes in measures of climate (such as temperature, precipitation, or wind) lasting for an extended period (decades or longer)" [6]. In this regard climate change is a change in statistical "measures of climate," which may or may not reflect a permanent change or shift in the 30-year average climate in any particular location. Climate change may result from natural factors, such as solar variability [7, 8]; sun spot prevalence [9]; slow changes in the Earth's orbit around the sun [10]; natural processes within the climate system (e.g. changes in ocean circulation) [11]; ocean surface temperature changes [12]; galactic cosmic rays [13]; changes in the earth's reflectance [14]); human activities (e.g. carbon dioxide emissions) [15]; and changes in the land surface (e.g. deforestation [16], reforestation [17], urbanization [18], and desertification [19]).

Weather is often defined as the atmosphere's condition at any given time and location. Metrics used to characterize weather and climate are identical (e.g. temperature, precipitation, wind, relative humidity, atmospheric pressure, cloud cover, solar intensity). Weather and climate have similar underlying physics. In practice, at any particular location, weather occurs from day to day whereas climate is what may be expected based on observations of weather over the prior 30-year period.

The study of climate and climate changes is the focus of variety of disciplines including those listed in Table 1. Each discipline and scientist function within a characteristic set of presuppositions. Given differences in methods and assumptions vigorous disagreement over climate data analysis and interpretation should be expected.

\section{Global Reference Frame Limitations}

Climate change is studied, assessed, and discussed within the global reference frame developed by the UN International Panel on Climate Change (IPCC) illustrated in Figure 4. A global frame of reference includes consideration of effects of the sun and planets [20]. Energy emitted by the sun enters the top of the earth's atmosphere (TOA). Some of this energy is reflected (albedo) and some is absorbed within the atmosphere and/or on the surface. At any particular point in time and location the global energy balance may favor warming or cooling. A solar frame of reference is implicitly assumed as each discipline (Table 1) studies one aspect or part (s) of the overall sun, planets, earth, atmosphere, climate system. GCMs are applied to simulate the behavior of the entire system and project future global temperature changes [21]. GCM projections may be downscaled to a regional level [22]. But there are serious limitations of a solar reference frame and GCMs in general discussed below.

\subsection{Surface Temperature Data Quality}

There are three primary global temperature data bases; the combined Climate Research Unit (CRU)-Hadley record (HADCRU), the National Aeronautic and Space Administration (NASA)-GISS (GISTEMP) record, and the National Oceanic and Atmospheric Administration (NOAA) record. All global surface temperature data bases rely on the same underlying archive of weather station data known as the Global Historical Climatology Network (GHCN) [23]. GHCN version 2 (GHCN v 2) compiles 31 different data archives each with differing amounts of coverage over time $[24,25]$. GHCN v 2 has some data from most places in the world, but continuous coverage for the whole of the $20^{\text {th }}$ century is limited to the United States, southern Canada, Europe and a few other locations. Global coverage is non-existent for maximum-minimum temperature data back to 1900 .

Table 1. Scientific disciplines studying climate.

\begin{tabular}{l}
\hline Discipline \\
\hline Atmospheric Science \\
Computer Science \\
Dendrochronology \\
Environmental Chemistry \\
Environmental Microbiology \\
Environmental Science \\
Environmental Engineering \\
Geology \\
Mathematics \\
Meteorology \\
Physics \\
Phytology \\
Public Health Science \\
Remote Sensing Science \\
Solar Science
\end{tabular}

The HADCRU, GISTEMP, and NOAA surface temperature archives rely on the same underlying input data and therefore are not independent data sets. Limitations of the GHCN affect all data sets. Sampling discontinuities, urbanization and land use changes have decreased the quality of GHCN data over time. Differences in data processing methods between research teams do not compensate for poor underlying data quality inherent in the GHCN data. A similar situation exists with historical Sea Surface Temperature (SST) data sets which are derived primarily from the International Comprehensive Ocean-Atmosphere Data Set (ICODADS) [23]. 


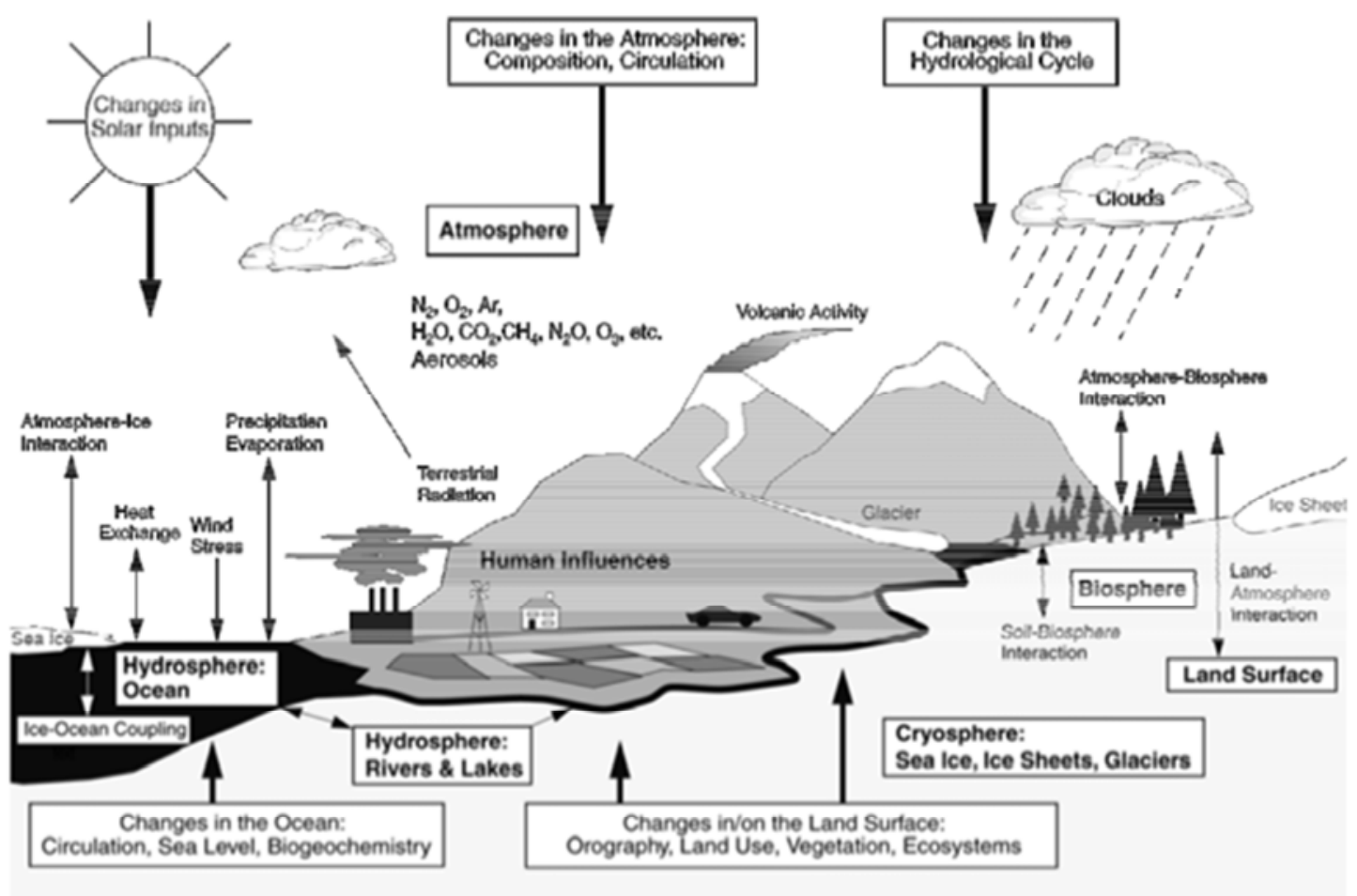

Figure 4. Global Climate System [20].

\subsection{Satellite Temperature Monitoring}

Since late 1978, polar-orbiting satellites have provided an important vantage point from which to monitor climate variability and change. Average air temperature over relatively deep atmospheric layers can be monitored using passive microwave radiometers measuring thermal microwave emission from molecular oxygen which is proportional to temperature. Changes in the temperature of atmospheric layers is directly related to changes in heat content due to climate changes. Satellite temperature data sets are maintained by the University of Alabama Huntsville (UAH) [26] and the Remote Sensing System (RSS) [27].

Three primary atmospheric layers are monitored: the lower troposphere (LT), mid-troposphere, and lower stratosphere. Adjustments to satellite monitoring data are necessary to account for calibration, orbit decay, viewing angle, and instrument temperature. Corrections for these effects may be well understood and straightforward (e.g. orbit decay) or poorly understood and empirical (e.g. instrument temperature effects). Both the UAH and RSS datasets are routinely adjusted for these effects. Global temperature trends are routinely published by researchers at UAH, University of Washington, NOAA and other institutions. In general, satellite temperature measurements provide the best overall indication of climate system responses.

The procedure for merging individual satellite observations into continuous, quality time series differs between research teams and institutions. Non-climatic biases include diurnal cycle drift effect, biases due to the decay of satellite orbits, frequency shifts in the radiometer, and influence of instrument body temperatures. Consequently, differences in data-merging procedures result in different global temperature trends being generated by different research teams [28]. Discussion of analytical differences can be quite spirited [29, 30, 31, 32]. However, alternate data-merging procedures may well be equally acceptable technically, and legitimate disagreements should be expected between equally competent research teams. Discrepancies between published satellite temperature trends and re-analysis of previously published data complicates practical application of these data. Indeed, analysis of previously published results based on arbitrary changes in the raw data and/or methods and assumptions made in order to achieve a desired result destroys the credibility of the analysis.

Satellite-based temperature measurements of the lower troposphere are typically reported as the difference between current temperatures and an arbitrary mean calculated over time. Figure 5 shows the trend of monthly global temperature anomalies beginning in 1979 when satellite-based measurements began to March 2017. The departure (anomaly) is the difference between the monthly mean and the mean for the 30 year period 1981-2010. Figure 6 compares the monthly global and northern hemisphere temperature anomalies. Figure 7 compares global average temperature with the global land and global surface temperature. The resulting trends show global temperature change but provide little insight as to the cause of climate changes and actual temperature variations. From such trends inferences must be 
made that changes in global average temperature correspond to fundamental changes in the climate system itself beyond natural internal variability. The horizontal temperature trend from approximately 1995 to the present may be attributed to internal climate variability $[33,34]$.

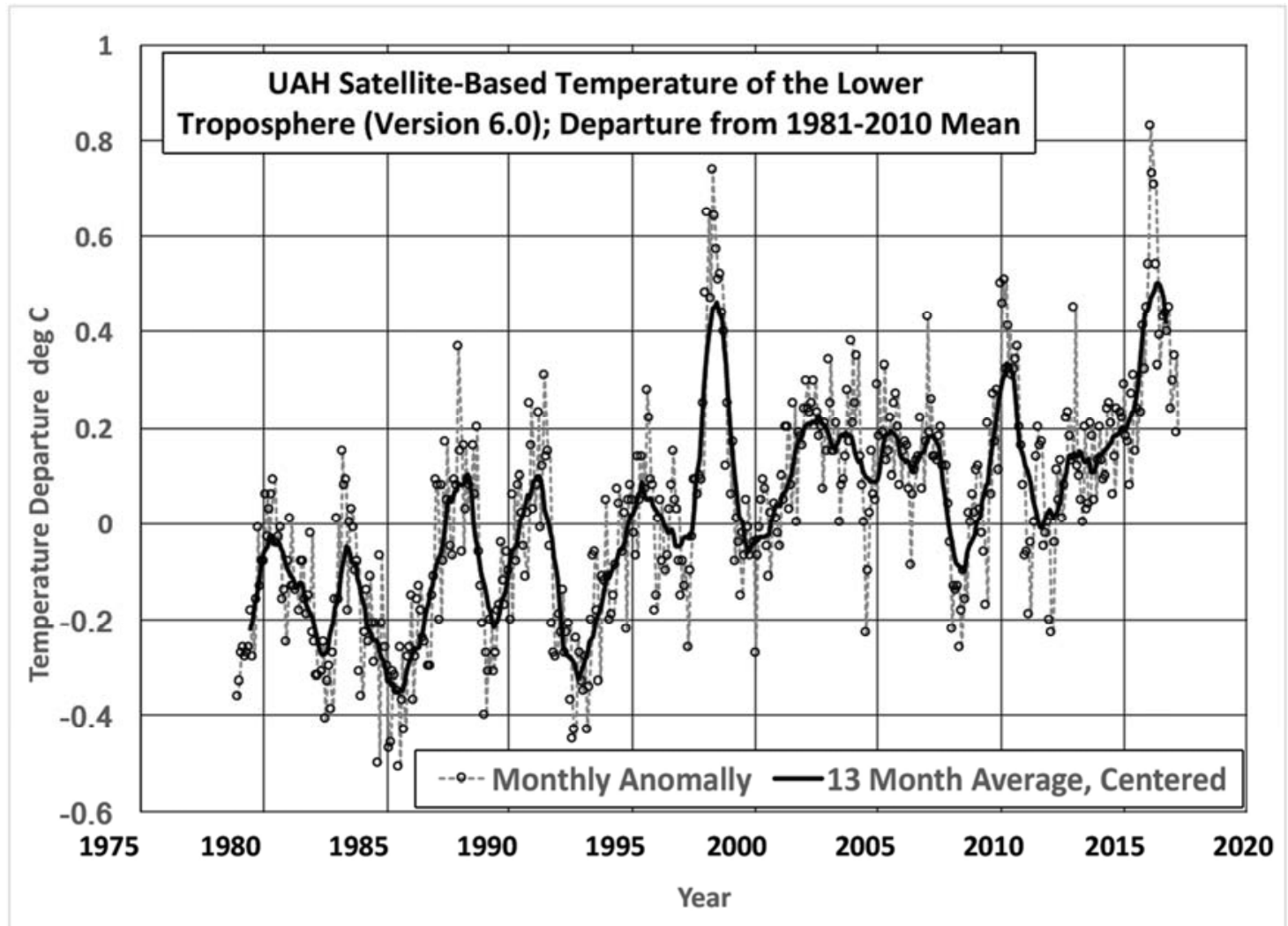

Figure 5. UAH Satellite-Based Lower Troposphere Monthly Temperature Departure from 1981-2010 Mean.

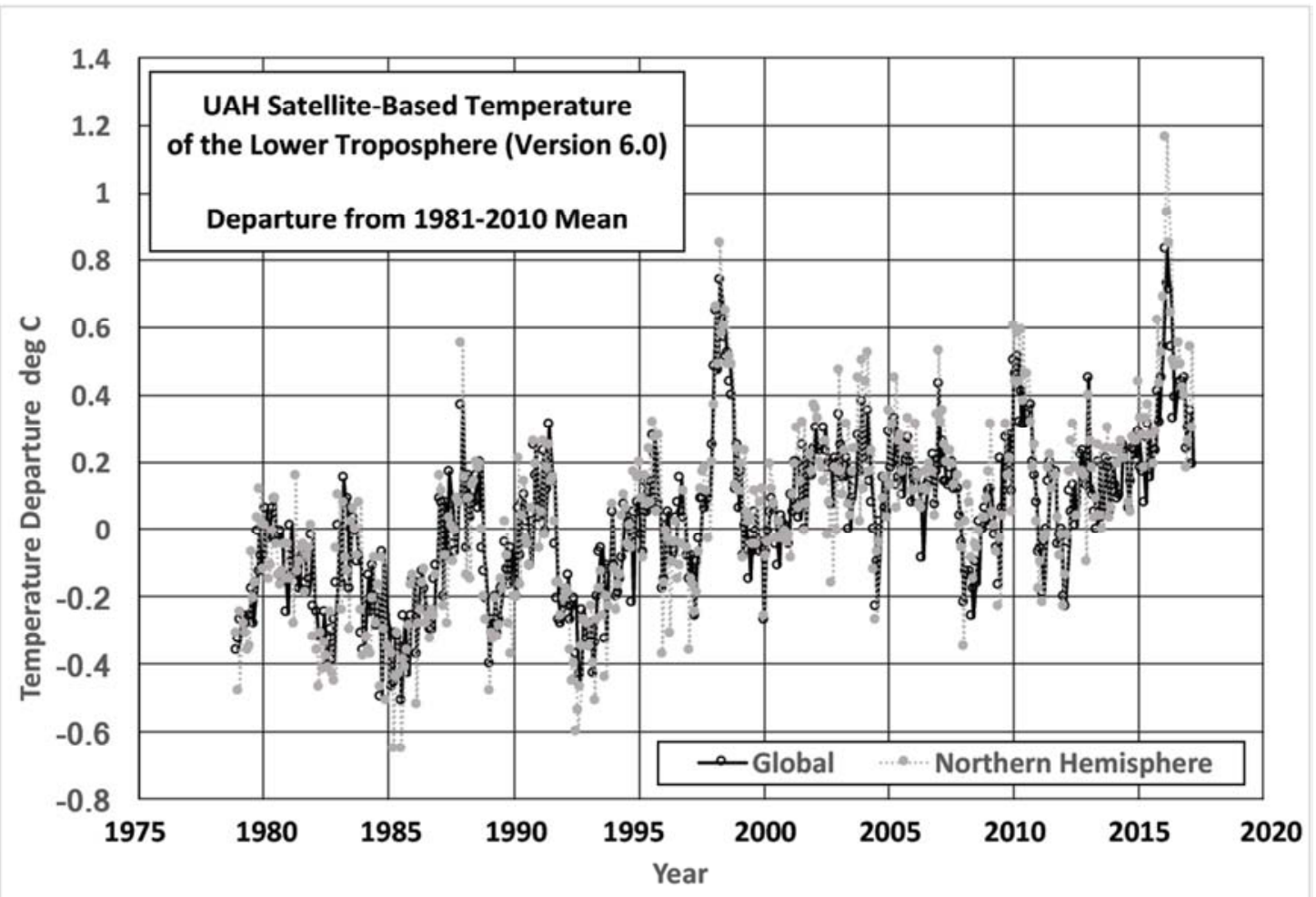

Figure 6. Global and Northern Hemisphere UAH Satellite-Based Lower Troposphere Monthly Temperature Departure from 1981-2010 Mean. 


\subsection{Computer Model Simulations}

The climate system is a highly non-linear complex system with many feedbacks both positive and negative. In the global reference frame, natural processes show variations at spatial and temporal scales. Indeed, the global climate system is continually changing and does not reach an equilibrium state. The global average TOA solar irradiance is $340 \pm 0.1$ $\mathrm{Wm}^{-2}$ and based on the best available information the resultant net energy flux to the earth is $0.6 \pm 0.4 \mathrm{Wm}^{-2}$ [35]. The energy difference between incoming solar irradiance and net energy flux to the earth drives global climate changes.

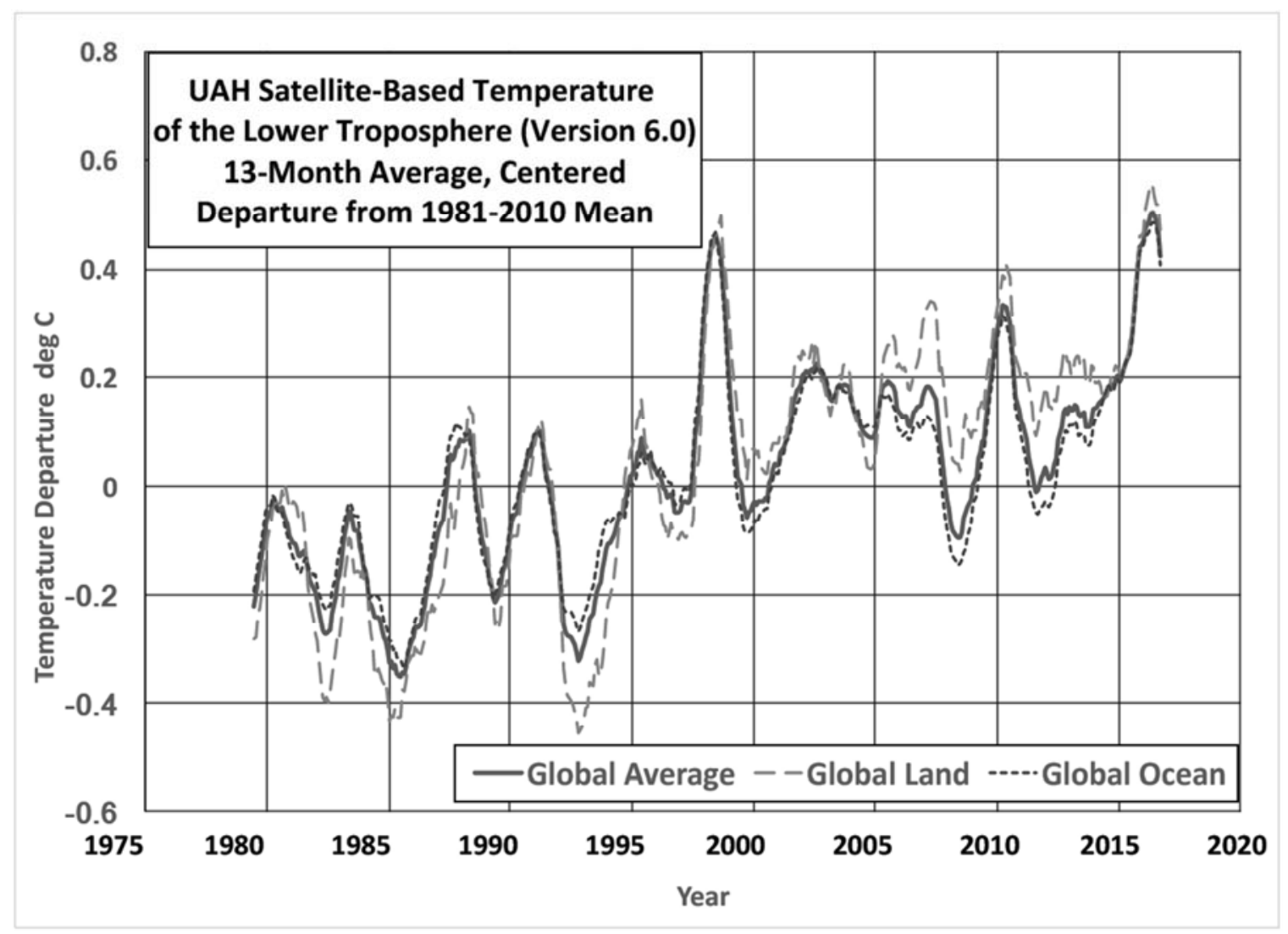

Figure 7. Global Average, Global Land, and Global Ocean Monthly Temperature Departure from 1981-2010 Mean.

Computer simulations involve mathematical models implemented on a computer imitating one or more natural processes. Models are based on general theories and fundamental principles, idealizations, approximations, mathematical concepts, metaphors, analogies, facts, and empirical data [36, 37]. Judgments and arbitrary choices must be made in model construction to apply fundamental laws to describe turbulent fluid flow. The large size and complexity of the atmosphere prohibit the direct application of general theory. Applying Navier-Stokes equations of fluid dynamics to the global atmosphere is not feasible even with the fastest computers. Models of the atmosphere rely on parameterizations of physical processes that cannot be directly simulated. A parameterization is a separate mathematical model calculating the net effects of unresolved processes on the processes that can be directly simulated [36].

Sophisticated climate models (coupled ocean-atmosphere GCMs) are very complex and apply a large number of input and feedback parameters. Such atmospheric models are useful but limited in their representation of underlying physical processes. Uncertainties in climate change attribution include internal climate variability, natural forcing, anthropogenic forcing, response patterns to natural and anthropogenic forcing, and discrepancies between observed and modeled temperature variations [38, 39, 40].

Simulation-based climate predictions use the method of ensemble prediction, producing multiple simulations for predictive periods of interest with differing initial conditions, parameter values and/or model structures. The predictions of GCMs and ensembles are highly uncertain [39]. In general, ensemble model forecasts have been found unreliable for long-term climate prediction [41, 42].

\section{The Locational Reference Frame}

Civil infrastructure once constructed is location-specific and does not change location relative to the earth's surface. To simplify conceptual analysis, a locational reference frame is presented here using the environmental engineering concept of "control volume." A control volume is an imaginary boundary around the particular volume of space 
under analysis. A global reference frame control volume is the entire global, with global climate changes are modeled within a formal coordinate system (Eulerian). In contrast, a locational reference frame consists of the perimeter around a particular location (e.g. city boundaries, city block, property lines), the earth's surface underlying the perimeter to define the bottom, and the air-space above the perimeter up to the height of the tallest structure to define the top. In the locational reference frame the control volume frame is considered fixed in space. The effects of global climate system are evaluated from the perspective of the local reference frame control volume (Lagrangian).

Within the locational reference frame standard metrics are used as measures of climate and weather (temperature, precipitation, wind, relative humidity, atmospheric pressure, cloud cover, solar intensity) to define the state of the atmosphere within the control volume. Of course, changes in weather and climate are occurring outside of the control volume and wind, solar energy, and moisture pass across the control volume boundaries resulting in changes in the state of the atmosphere within the control volume (the locational reference frame). In response to global and regional climate and weather changes the overall atmospheric system will naturally adjust resulting in changes in climate metrics within the locational reference frame. Changes in temperature within the locational reference frame indicate directly the impact of global or regional weather or climate changes on that particular locational reference frame.

\section{Example Application of a Locational Reference Frame}

The City of Riverside is located in Southern California. Named for its location beside the Santa Ana River, the city has a population of 303,871 people (2010). Riverside is the largest city in Riverside County as well as the surrounding metropolitan area known as the Inland Empire. It is the $12^{\text {th }}$ most populous city in the State of California and the $59^{\text {th }}$ most populous city in the United States. It has a temperate climate. For the 30-year period 1981-2010, Riverside had a mean annual precipitation of $12.4 \mathrm{in} / \mathrm{yr}$, a mean daily temperature of $17.1^{\circ} \mathrm{C}$, a mean daily maximum temperature of $25.9^{\circ} \mathrm{C}$, and a mean daily minimum temperature of $11.61^{\circ} \mathrm{C}[43]$.

Data were obtained from NOAA's National Centers for Environmental Information (NCEI) Historical Observing Metadata Repository (HOMR) for two GHCN weather stations in the city. Temperature data from April 1, 1998 to April 28, 2017 were available for GHCN station USC 00047470, Riverside Fire Station No. 3 and GHCN station USW 00003171, Riverside Municipal Airport.

\subsection{Riverside Fire Station No. 3}

Riverside Fire Station No. 3 (USC 00047470) is located in the downtown area of Riverside (33 $57^{\prime} 04^{\prime \prime} \mathrm{N}, 117^{\circ} 23^{\prime} 17^{\prime}$ 'W). Maximum and minimum temperature data from 1901 to 2016 are presented in Figure 8 as time series plots. Maximum daily temperatures fall within a consistent band between approximately 5 to $45^{\circ} \mathrm{C}$ during the entire 115 -year period. Minimum daily temperatures fall within a fairly consistent band between approximately -5 to $25^{\circ} \mathrm{C}$ during this period. The range of daily temperatures (maximum daily temperature minus minimum daily temperature) shown in Figure 9 also demonstrates a consistent horizontal trend.

The maximum and minimum daily temperature data from 1901 to 2016 were also compared to the daily normal temperatures (NORM) calculated by NOAA for the 30-year period 1981 to 2010 [43]. Figure 10 shows the departure (measured temperature minus NORM) for maximum daily temperatures (upper) and minimum daily temperatures (lower). Both follow a horizontal trend within a wide variability band during the entire 115-year period.

\subsection{Riverside Municipal Airport}

Riverside Municipal Airport (GHCND USC 00003171) is located approximately $7 \mathrm{~km}$ southwest of downtown Riverside (33 $\left.57^{\prime} 07^{\prime} \mathrm{N}, 117^{\circ} 26^{\prime} 19^{\prime \prime} \mathrm{W}\right)$. Maximum and minimum temperature data from 1998 to 2017 are presented in Figure 11 as time series plots. Maximum daily temperatures fall within a consistent band between approximately 10 to $45^{\circ} \mathrm{C}$ during the entire 28 -year period. Minimum daily temperatures fall within a fairly consistent band between approximately -5 to $25^{\circ} \mathrm{C}$ during this period. The range of daily temperatures (maximum daily temperature minus minimum daily temperature) shown in Figure 12 also demonstrates a consistent horizontal trend.

The maximum and minimum daily temperature data from 1998 to 2017 were also compared to the daily NORM calculated by NOAA for the 30-year period 1981 to 2010 [43]. Figure 13 shows the departure (measured temperature minus NORM) for maximum daily temperatures (upper) and minimum daily temperatures (lower). Both follow a horizontal trend within a wide variability band during the 28-year period.

Average daily temperature data are available only for the Riverside Municipal Airport from 1998 to 2005 presented in Figure 14 . The average daily temperature followed a wide horizontal temperature band from about 5 to $33^{\circ} \mathrm{C}$ during this 6-year period. The departure of the average daily temperature from the 1981-2010 NORM also follows a consistent horizontal trend (Figure 15).

\subsection{Temperature Trend Evaluation}

The maximum, minimum, and average daily temperatures for the Riverside Fire Station No. 3 and Riverside Municipal Airport fall within a wide horizontal temperature band throughout their respective monitoring periods. Within a locational reference frame, temperature changes within the control volume reflect the atmospheric and climate changes occurring outside of the control volume. The change in temperature and temperature trends measured directly reflect climate changes (e.g. increased carbon dioxide) impacting 
the locational reference frame. These temperature data suggest that the 30-year average climate of Riverside overall has been relatively consistent with wide day-to-day temperature variations from 1901 to 2017. A slight increase in minimum daily temperature is noticeable at Riverside Fire Station No. 3 after 1998 (Figure 8, lower) with a corresponding slight decrease in the daily temperature range (Figure 9). This trend is most likely due to the urban heat island effect [44] resulting from increased development within and around downtown Riverside over this extended period.
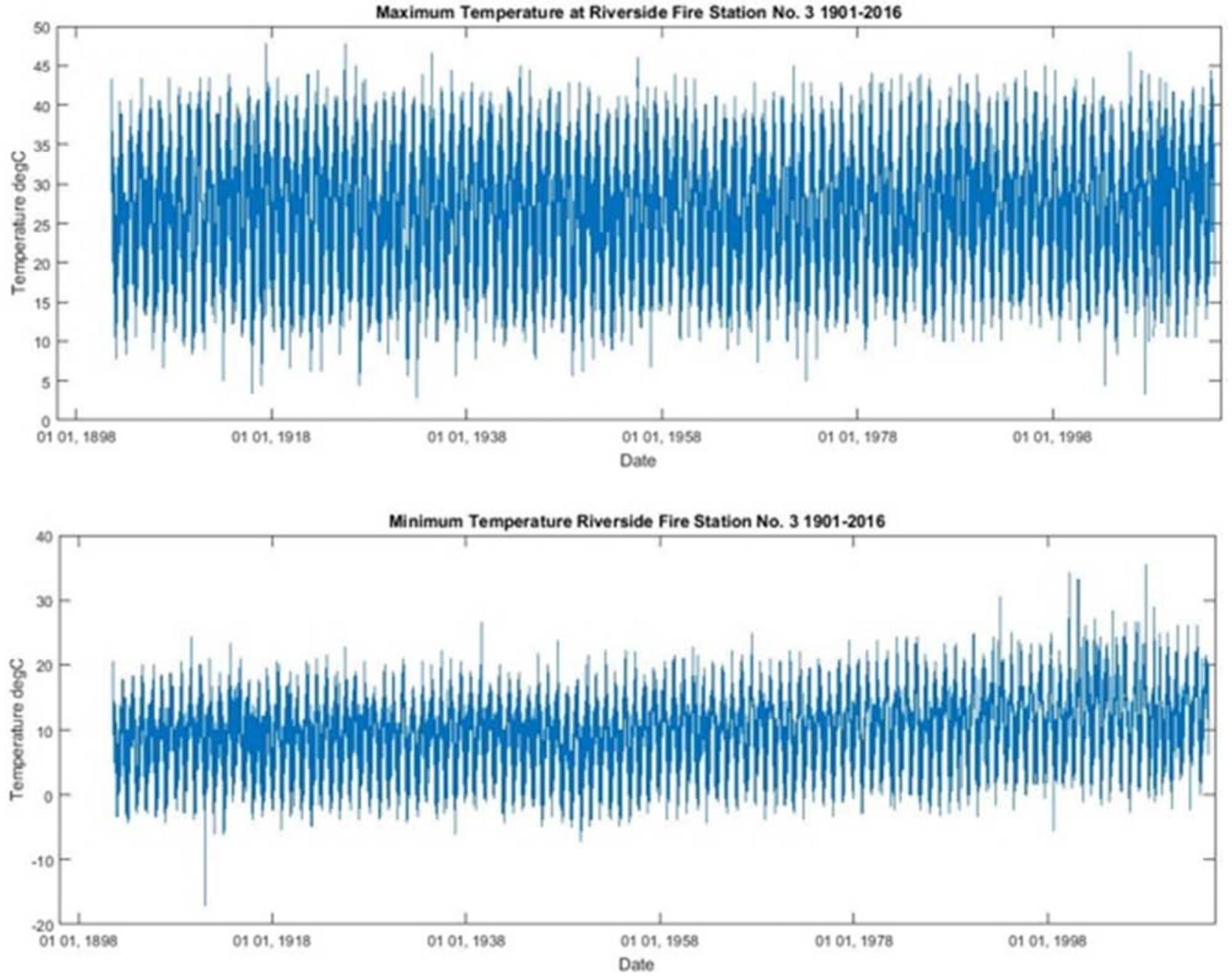

Figure 8. Riverside Fire Station No. 3 maximum daily temperature (upper) and minimum daily temperature (lower), $1901-2016$.

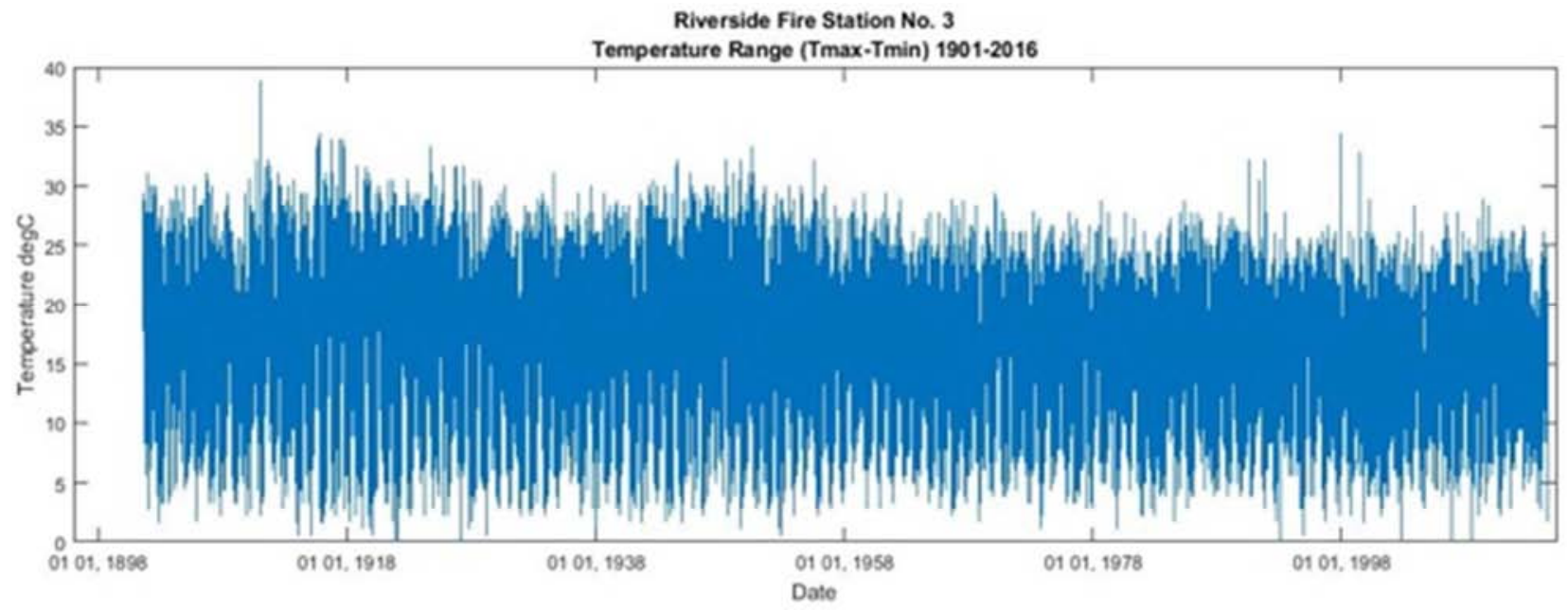

Figure 9. Riverside Fire Station No. 3 daily temperature range (maximum temperature minus minimum temperature). 

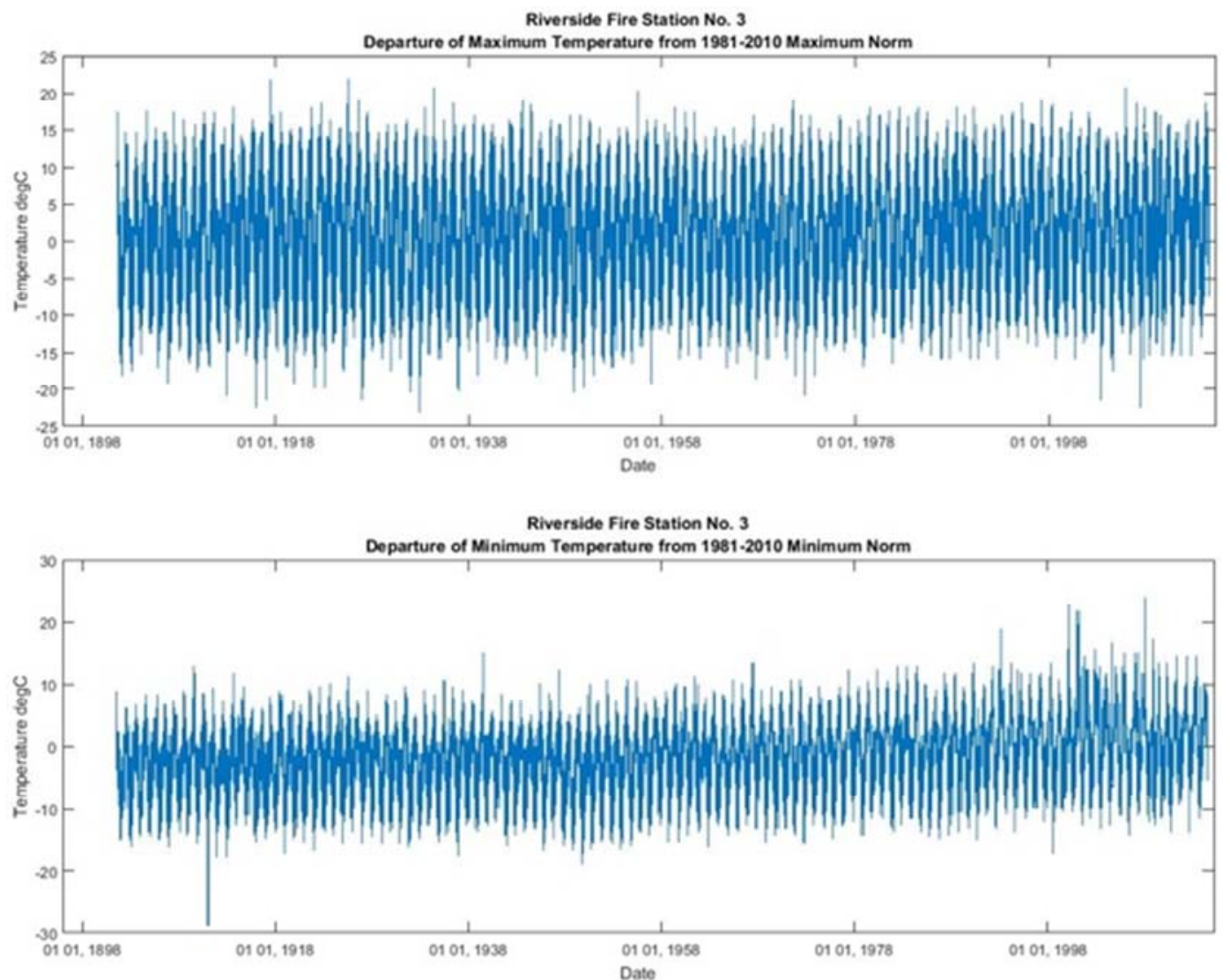

Figure 10. Riverside Fire Station No. 3 maximum daily temperature (upper) and minimum daily temperature (lower) departure from the 1981-2010 daily maximum and minimum NORMs.
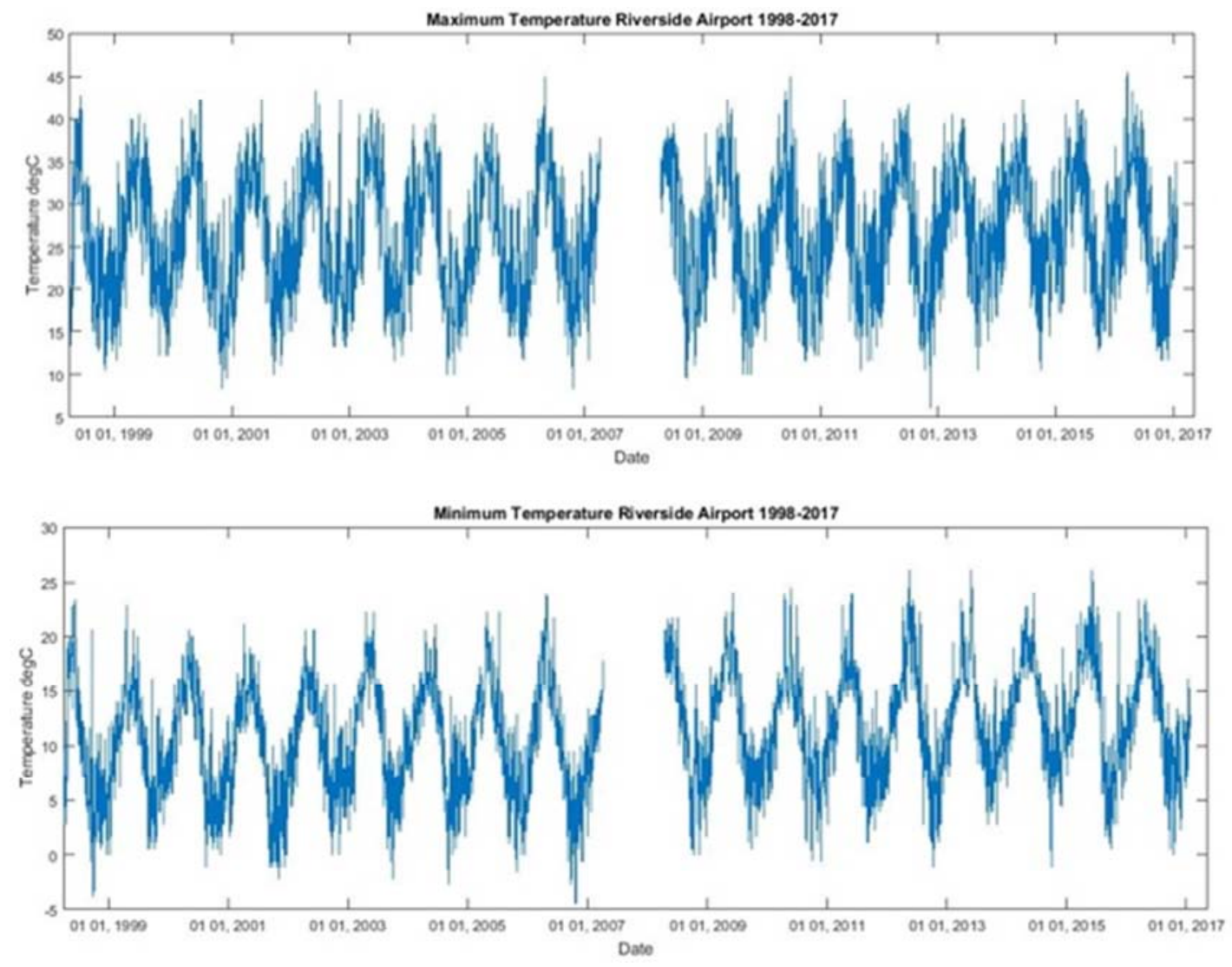

Figure 11. Riverside Airport maximum (upper) and minimum (lower) daily temperatures, 1998-2017. 


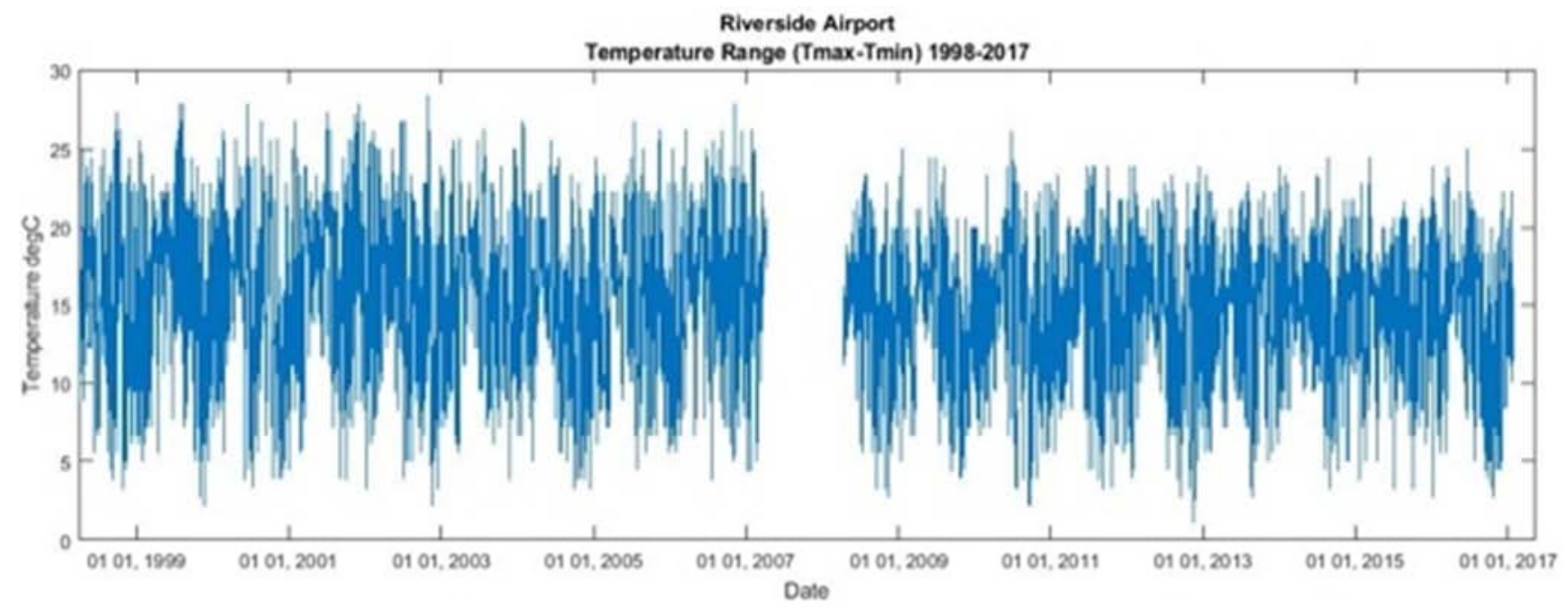

Figure 12. Riverside Airport daily temperature range (maximum temperature minus minimum temperature), $1998-2016$.
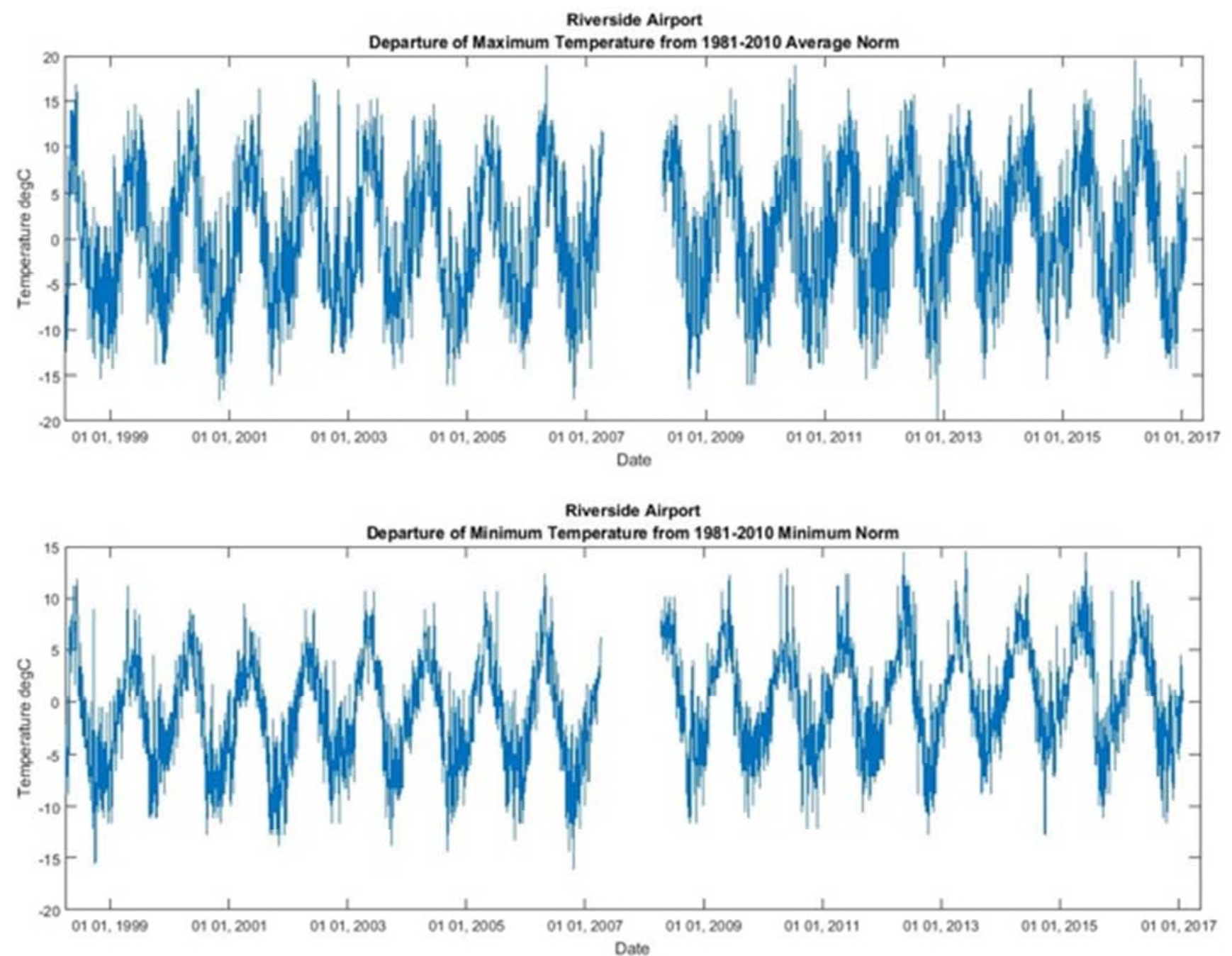

Figure 13. Riverside Airport maximum daily temperature (upper) and minimum daily temperature (lower) departure from the 1981-2010 daily average temperature NORM. 


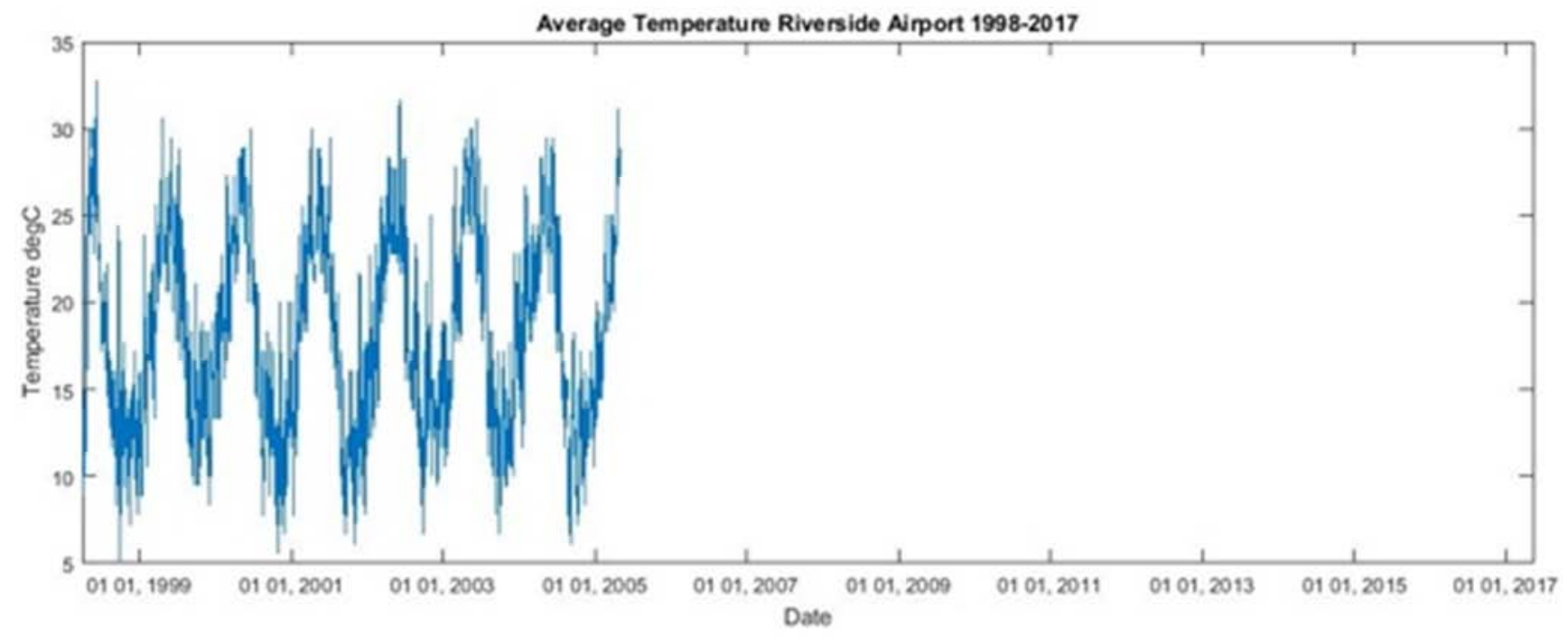

Figure 14. Riverside Airport average daily temperature, 1998-2017.

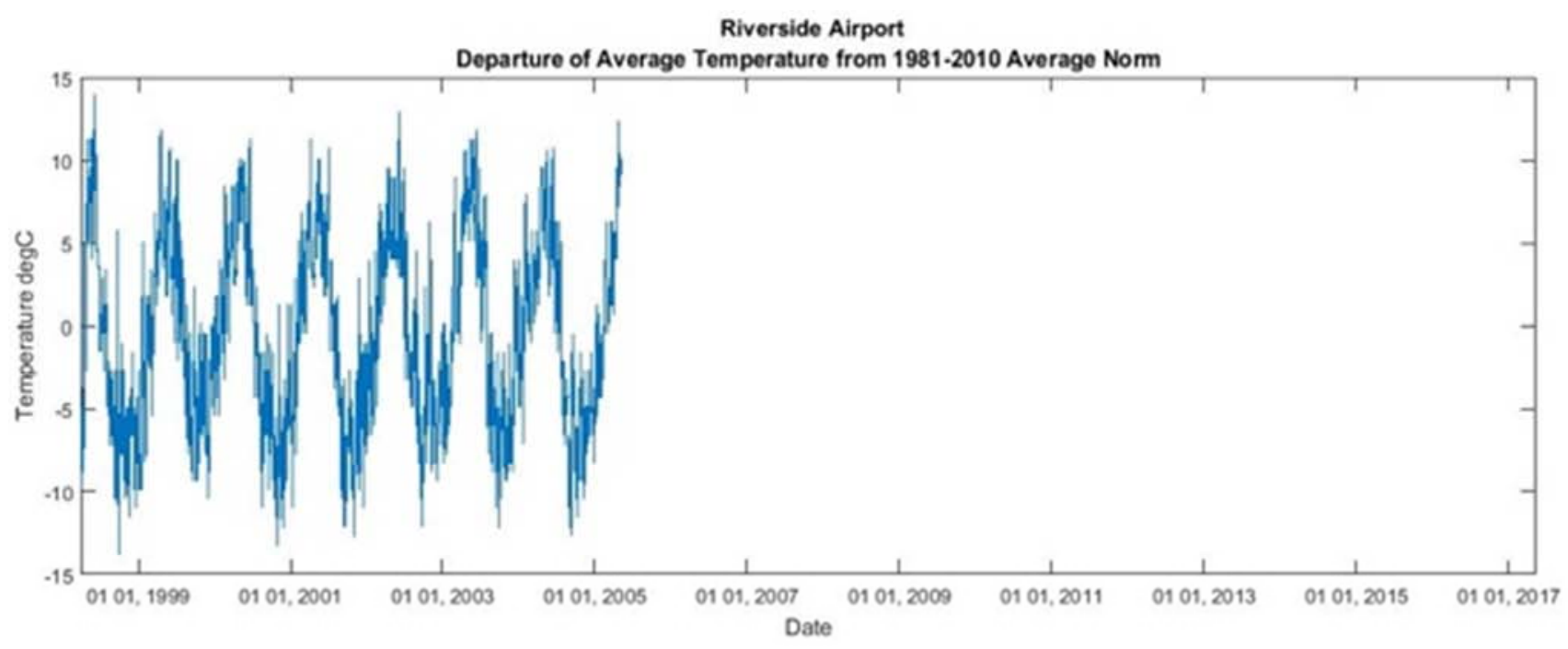

Figure 15. Riverside Airport average daily temperature departure from the 1981-2010 daily average temperature NORM.

\subsection{Potential Impact of Carbon Dioxide}

$\mathrm{CO}_{2}$ is a non-toxic trace gas constituting approximately $0.04 \%$ of the earth's atmosphere. The global atmospheric concentration of $\mathrm{CO}_{2}$ increased from a pre-industrial value of about 280 ppmv to 379 ppmv in 2005 [45]. The average $\mathrm{CO}_{2}$ concentration at the monitoring station at Mauna Loa, Hawaii for May 2017 is 409.65 ppmv [46].

A rising concentration of atmospheric $\mathrm{CO}_{2}$ will contribute to warming of the Earth's atmosphere. The physics of $\mathrm{CO}_{2}$ in the atmosphere is very different than the physics of the heating effect occurring in a physical "greenhouse" for growing plants [47]. The term "greenhouse effect" is commonly used to refer to the warming of the earth from "greenhouse" gases such as $\mathrm{CO}_{2}$ in the atmosphere. The term "greenhouse" is not used here to refer to the Earth's warming to avoid equivocation.

The impact of future atmospheric $\mathrm{CO}_{2}$ warming on the Riverside locational reference frame must be estimated. GCMs could be applied to project future global temperatures and those projections could be downscaled to the Riverside area. However, such efforts would be potentially misleading because of the limitations of GCMs discussed previously.

Detailed assessments of the $\mathrm{CO}_{2}$ effect have been performed analyzing the Earth's energy balance in the total atmosphere column and the reduction of the upward infrared radiation emission at the tropopause. The impact of $\mathrm{CO}_{2}$ on warming of the Earth is expressed in terms of "climate sensitivity," which is the amount of warming that could be expected as a result of doubling of the $\mathrm{CO}_{2}$ concentration.

Estimates of climate sensitivity differ widely suggesting that this characteristic of the climate system is not well-understood [48]. A simple model predicts that a doubling of the $\mathrm{CO}_{2}$ concentration in the atmosphere would result in a small increase of the Earth's surface temperature, from approximately 0.4 to $<0.7^{\circ} \mathrm{C}$ [49]. A best estimate of $2.0^{\circ} \mathrm{C}[50]$ is assumed here. If $\mathrm{CO}_{2}$ increases at the current rate of approximately 2 ppmv per year, a temperature increase of approximately $0.009^{\circ} \mathrm{C} / \mathrm{yr}$ could be expected. 


\section{Results and Discussion}

A primary objective of Civil and Environmental Engineering (CEE) is to plan, design, and build infrastructure sustainable over multiple decades (e.g. 20, 30, 50 years). Successful CEE infrastructure projects provide one or more critical functions necessary for long-term sustainable cities (Table 2). Infrastructure is needed by people regardless of the country's, city's or area's level of economic development or social status. Sustainability of civil infrastructure must be addressed locally on four dimensions: technical capacity, financial viability, social acceptability, and environmental effects.

Global surface temperature data bases rely on the same underlying GHCN archive of weather station data. The poor data quality of this data base is well-documented [23] and confirmed in this study. Only maximum and minimum surface temperature data are available for the Riverside Fire Station No. 3 (USC00047470) from 1901 to 2016. Average temperature data are not available for this location. Average temperature data are available for the Riverside Municipal Airport (USC00003171) only from 1998 to 2005. Data from both stations are inadequate for assessing long-term average temperature trends. Interpretations and conclusions drawn using these data will be determined by the methods of analysis and assumptions. Here data are plotted using simple time series to reveal general trends. Although more advanced statistical analysis is possible, additional insight from such an analysis is unlikely given limited data.

To date the impact of $\mathrm{CO}_{2}$ is assessed universally within a global reference frame. Although atmospheric $\mathrm{CO}_{2}$ has steadily increased the average satellite global temperatures (Figures 5, 6, 7) have flattened since approximately 1995. From such trends, it must be inferred that changes in global lower troposphere average temperature correspond to fundamental changes in the climate system beyond internal variability.

Available temperature data from both the Riverside Fire Station No. 3 and the Riverside Municipal Airport demonstrate horizontal trends within a wide band of variability. Historical evidence of a significant increase in surface temperatures due to increases in atmospheric $\mathrm{CO}_{2}$ is absent from these data.

GCMs and ensemble climate models are useful but limited in their representation of underlying physical processes. Uncertainties and other limitations discussed previously render such models unreliable for long-term global temperatures or local climate change prediction.

Table 2. Functions of Infrastructure. (Adapted from [3]).

\begin{tabular}{ll}
\hline Function & Scope \\
\hline 1. Move People & Streets, Highways, Subway, Bridges, Tunnels \\
2. Move Freight & Railroad, Maritime, Air Cargo, Local Markets \\
3. Provide Power & Electricity, Natural Gas, Steam, Nuclear, Solar, Wind, Biofuels, Wave \\
4. Provide Communications & Telephone, Mail, Airways, Digital, Internet \\
5. Provide Water and Sanitation & Drinking Water, Sewage Treatment, Solid Waste Disposal \\
6. Provide Essential Structures & Housing, Office Buildings, Manufacturing, Retail and Trade, Public Buildings \\
\hline
\end{tabular}

Sustainability of civil infrastructure must be addressed locally in 4-dimensions: technical sufficiency, financial viability, social acceptability, and environmental effects. To succeed long-term, a civil infrastructure project must be sustainable in all 4 dimensions. Infrastructure is stationary and therefore local. Temperatures within a locational reference frame change in response to global climate changes providing a direct assessment of global climate changes on a particular location.

Climate sensitivity may be applied to estimate the warming effect of $\mathrm{CO}_{2}$ on the locational reference frame. Factors affecting Climate Sensitivity are not well-understood and estimates differ among researchers. Alternatively, a site-specific model could be developed to estimate the future impact of $\mathrm{CO}_{2}$ warming on a particular location. If atmospheric $\mathrm{CO}_{2}$ continues to increase at its current rate the small annual temperature increase expected at Riverside will likely be insignificant (e.g. $<0.01^{\circ} \mathrm{C} / \mathrm{yr}$ ) compared to natural temperature variability.

\section{Conclusion}

This study introduces the concept of a locational reference frame for assessing the impact of $\mathrm{CO}_{2}$ on the sustainability of civil infrastructure. GHCND temperature data for the City of Riverside, California was analyzed to illustrate application of a locational reference frame. Additional development of the locational reference frame concept is needed to incorporate other weather and climate metrics (e.g. rainfall) as well other environmental effects. The locational reference frame provides a practical perspective useful for $\mathrm{CEE}$ project planning today.

\section{References}

[1] R. W. Kates, T. M. Parris, and A. A. Leiserowitz. 2005. What is Sustainable Development? Environment, 47, 3 (2005) 9-21.

[2] City of Riverside, Captial Improvement Program Summary, http://www.riversideca.gov/finance/PDF/budget-1618/Commu nityImprovementProgramSummary.pdf Accessed May 15, 2017.

[3] C. D. Martland. Toward More Sustainable Infrastructure; Project Evaluation for Planners and Engineers. 2012 Hoboken, NJ: John Wiley and Sons.

[4] R. S. Lindzen. Global Warming: How to approach the science. Fourth International Conference on Climate Change, May 16, 2010, Heartland Institute, Chicago. 
[5] A. Arguez, R. S. Vose. The Definition of the Standard WMO Climate Normal. Bulletin of the American Meteorological Society 6 (2011) 699-704.

[6] USEPA 2010. USEPA Climate Change Web Page; Basic Information.

http://www.epa.gov/climatechange/basicinfo.html (Accessed May 20, 2010).

[7] W. Soon, R. Connolly, M. Connolly. Re-evaluating the role of solar variability on Northern Hemisphere temperature trends since the $19^{\text {th }}$ century. Earth-Science Reviews, 150 (2015) 409-452.

[8] L. J. Grey, W. Ball, S. Misios. Solar Influences on climate over the Atlantic/European Sector. Radiation Processes in the Atmosphere and Ocean (IRS 2016) AIP Conf. Proc. 1810, 020002-1-020002-8.

[9] A. I. Shapiro, W. Schmutz, E. Rozanov, M. Schoell, M. Haberreiter, A. V. Shapiro, S. Nyeki. A new approach to long-term reconstruction of the solar irradiance leads to large historical solar forcing. Astronomy and Astrophysics (2011) arXiv: $1102.4763 \mathrm{v} 1$.

[10] N. Scafetta. Testing an astronomically-based decadal-scale empirical harmonic climate model versus the IPCC (2007) general circulation climate models. Journal of Atmospheric and Solar-Terrestrial Physics 80 (2012) 124-137.

[11] G. Ja. Khachikjan, G. J. Kofko. On 3 to 6 year cycles in the time of geomagnetic storm sudden commencement occurrence and ENSO climate cycles. Advances in Geosciences, 6 (2006) 87093.

[12] S.-L. Yao, J.-J. Luo, G. Huang, P. Wang. Distinct global warming rates tied to multiple ocean surface temperature changes. Nature Climate Change (2017).

[13] H. Svensmark, M. B. Enghoff, J. O. P. Pedersen. Response of Cloud Condensation Nuclei $(>50 \mathrm{~nm})$ to changes in ion-nucleation (2011) arXiv: 1202.5156 [physics.atm-clus].

[14] P. R. Goode, E. Pallé. Shortwave forcing of the Earth's climate: Modern and historical variations in the Sun's irradiance and the Earth's reflectance. Journal of Atmospheric and Solar-Terrestrial Physics 69 (2007) 1556-1568.

[15] W. Knorr. Is the airborne fraction of anthropogenic $\mathrm{CO} 2$ emissions increasing? Geophysical Research Letters 36, 21 (2009) L 21710.

[16] P. Longaboardi, A. Montenegro, H. Beltrami, M. Eby. 2016. Deforestation Induced Climate Change: Effects of Spatial Scale. PLoS ONE 11, 4 (2016) e 0153357.

[17] L. Huang, J. Liu, Q. Shao, X. Xu. Carbon sequestration by forestation across China: Past, present, future. Renewable and Sustainable Energy Reviews, 16, 2 (2012) 1291-1299.

[18] M. Higashino, H. G. Stefan. Hydro-climatic Change in Japan (1906-2005): Impacts of Global Warming and Urbanization. Air, Soil and Water Research, 7 (2014) 19-34.

[19] Y. Wang, X. Yan, Z. Wang 2016. A preliminary study to investigate the biogeophysical impact of desertification on climate based on different latitudinal bands. International Journal of Climatology, 36, 2 (2016) 945-955.

[20] IPCC. Climate Change: The Scientific Basis. Contribution of Working Group I to the Third Assessment Report of the
Intergovernmental Panel on Climate Change, Cambridge, England: Cambridge University Press.

[21] G. A. Meehl, W. M. Washington, J. M. Arblaster, A. Hu, H. Teng, C. Tebaldi, B. N. Sanderson, J.-F. Lamarque, A. Conley, W. G. Strand, and J. B. White. Climate System Response to External Forcings and Climate Change Projections in CCSM 4. Journal of Climate, 25 (2012) 3661-3683.

[22] C. M. Cooney. Downscaling Climate Models; Sharpening the Focus on Local-Level Changes. Environmental Health Perspectives, 120, 1 (2012) A 22-A 28.

[23] R. McKitrick. A Critical Review of Global Surface Temperature Data Products. (August 5, 2010). http://dx.doi.org/10.2139/ssrn.1653928.

[24] T. C. Peterson, R. S. Vose. An Overview of the Global Historical Climatology Network Temperature Database. Bulletin of the American Meteorological Society 78 (1997) 2837-2849.

[25] T. C. Peterson, R. S. Vose, R. Schmoyer, V. Razuavev. Global Historical Climatological Network (GHCN) Quality Control of Monthly Temperature Data. International Journal of Climatology 18 (1998) 1169-1179.

[26] R. W. Spencer, J. R. Christy. Precise monitoring of global temperature trends from satellites. Science, 247 (1990) 1558-1562.

[27] C. A. Mears, M. C. Schabel, F. J. Wentz. A reanalysis of the MSU channel 2 tropospheric temperature record. J. Climate, 16 (2003) 3650-3664.

[28] S. Po-Chedley, T. J. Thorsen, Q. Fu. Removing Diurnal Cycle Contamination in Satellite-Derived Tropospheric Temperatures: Understanding Tropical Troposphere Trend Discrepancies. J. Climate, 28 (2015) 2274-2290.

[29] S. Po-Chedley, Q. Fu. A Bias in the Midtropospheric Channel Warm Target Factor on the NOAA-9 Microwave Sounding Unit. J. Atmos. Oceanic Technol. 29 (2012) 646-652.

[30] J. R. Christy, R. W. Spencer. Comments of A bias in the midtropospheric channel warm target factor on the NOAA-9 Microwave Sounding Unit. J. Atmos. Oceanic Technol., 30 (2013) 1006-1013.

[31] S. Po-Chedley, Q. Fu. Reply to "Comments on 'A Bias in the Midtropospheric Channel Warm Target Factor on the NOAA-9 Microwave Sounding Unit"' Jour. Atmos. Oceanic Technol. 30 (2013) 1014-1020.

[32] R. E. Swanson. A Comparative Analysis of Data Derived from Orbiting MSU/AMSU Instruments. J. Atmos. Oceanic Technol. 34 (2017) 225-232.

[33] S.-L. Yao, G. Huang, R.-G. Wu, X. Qu. The global warming hiatus - a natural product of interactions of a secular warming trend and a multi-decadal oscillation. Theor Appl Climatol 123 (2016) 349-360.

[34] C. Hedemann, T. Mauritsen, J. Jungclaus and J. Marotzke 2017. The subtle origins of surface-warming hiatuses. Nature Climate Change, 7 (2017) 336-339.

[35] G. L. Stephens, T. L'Ecuyer. The Earth's energy balance. Atmospheric Research, 166 (2015) 195-203.

[36] A. E. Petersen. Simulating Nature. A Philosophical Study of Computer-Simulation Uncertainties and Their Role in Climate Science and Policy Advice. (2006) Het Spinhuis, Amsterdam. 
[37] G. A. Meehl, W. M. Washington, J. M. Arblaster, A. Hu, H. Teng, C. Tebaldi, B. N. Sanderson, J.-F. Lamarque, A. Conley, W. G. Strand, J. B. White. Climate System Response to External Forcings and Climate Change Projections in CCSM 4. J. Climate, 25 (2012) 3661-3683.

[38] S. Kravtsov. Pronounced differences between observed and CMIP 5-simulated multidecadal climate variability in the twentieth century. Geophysical Research Letters 44 (2017) 5749-5757.

[39] W. S. Parker 2010. Predicting weather and climate: Uncertainty, ensembles and probability. Studies in History and Philosophy of Modern Physics. 41 (2010) 263-272.

[40] C. A. Varotsos, M. N. Efstathiou, A. P. Cracknell. Plausible reasons for the inconsistencies between the modelled and observed temperatures in the tropical troposphere. Geophysical Research Letters 40, 18 (2013) 4906-4910.

[41] K. C. Green, J. S. Armstrong. Global Warming: Forecasts by Scientists versus Scientific Forecasts. Energy and Environment 18 (2007) 997-1021.

[42] D. T. Milhailovic, G. Mimic, I. Arsenic. Climate Predictions: The Chaos and Complexity in Climate Models. Advances in Meteorology (2014) Article ID 878249.

[43] NOAA National Centers for Environmental Information. National Environmental Satellite, Data, and Information
Service. Summary of Monthly Normals 1981-2010. Riverside Municipal Airport, CA US GHCND: USW 00003171. Generated on $05 / 02 / 2017$.

[44] B. Y. Tam, W. A. Gough, T. Hohsin. The impact of urbanization and the urban heat island effect on day to day temperature variation. Urban Climate 12 (2015) 1-10.

[45] Intergovernmental Panel on Climate Change. Climate Change 2007: Synthesis Report p 37.

[46] NOAA Earth System Research Laboratory Global Monitoring Division. Trends in Atmospheric Carbon Dioxide. https://www.esrl.noaa.gov/gmd/ccgg/trends/ (Accessed June 29, 2017)

[47] G. Gerlich, R. D. Tscheuschner. Falsification of the atmospheric $\mathrm{CO}_{2}$ greenhouse effect within the frame of physics. International Journal of Modern Physics B, 23 (2009) 275-364.

[48] S. S. Schwartz, R. J. Charlson, R. Kahn, H. Rodhe. Earth's Climate Sensitivity: Apparent Inconsistencies in Recent Assessments. Earth's Future, 2 (2014) 601-605.

[49] Y. V. Kissin. A simple alternative model for the estimation of the carbon dioxide effect on the Earth's energy balance. Energy and Environment 26 (2013) 1319-1333.

[50] A. Otto et al. Energy budget constraints on climate response. Nature Geoscience, 6 (2013) 415-416. 